\title{
Relationship Between IGF-1 and Cortisol/ DHEA-S Ratio in Adult Men With Diabetic Metabolic Syndrome Versus Non-Diabetic Metabolic Syndrome
}

\author{
Mervat M El-Eshmawy ${ }^{\mathrm{a}, \mathrm{c}}$, Asmaa Hegazy ${ }^{\mathrm{a}}$, Azza A El-Baiomy ${ }^{\mathrm{b}}$
}

\begin{abstract}
Background: Metabolic syndrome (MS) is a strong risk factor for cardiovascular disease and type 2 diabetes mellitus. Previous studies have suggested that low insulin like growth factor-1 (IGF1), low dehydroepiandrosterone sulfate (DHEA-S) and high cortisol are significant correlates of MS. The aim of the present study was to examine the relationships between serum IGF-1, cortisol, DHEA-S and cortisol/ DHEA-S ratio in adult men with MS either diabetic or non-diabetic.
\end{abstract}

Methods: One hundred adult men were enrolled in this study, divided into three groups: group 1 included 30 patients with diabetic MS, group 2 included 30 patients with non-diabetic MS and group 3 included 40 age and sex-matched controls. Anthropometric measurements, Homeostasis model assessment of insulin resistance (HOMA), lipid profile, IGF-1, cortisol, DHEA-S and cortisol/ DHEA-S ratio were assessed.

Results: IGF-1 and DHEA-S levels were significantly lower while serum cortisol and cortisol/ DHEA-S ratio were higher in both diabetic MS and non-diabetic MS adult men than healthy controls; they were also significantly different in the diabetic than in non-diabetic adult men with MS. IGF-1 was significantly and independently correlated with waist circumference, blood pressure, fasting blood glucose, HOMA, cortisol, DHEA-S and cortisol/ DHEA-S ratio. Cortisol/ DHEA-S ratio was significantly

Manuscript accepted for publication October 12, 2011

${ }^{a}$ Internal Medicine Department, Mansoura Specialized Medical Hospital, Faculty of Medicine, Mansoura University, Egypt

${ }^{\mathrm{b}}$ Clinical Pathology Department, Faculty of Medicine, Mansoura University, Egypt

${ }^{\mathrm{c}}$ Corresponding author: Mervat M El-Eshmawy,

Email: mervat2040@yahoo.com

doi: $10.4021 /$ jem $43 \mathrm{w}$ and independently correlated with blood pressure, fasting blood glucose, insulin, HOMA, triglyceride, high density lipoprotein cholesterol, cortisol and DHEA-S.

Conclusions: IGF-1 concentration is reduced and cortisol/ DHEA$\mathrm{S}$ ratio is increased along with insulin resistance in adult men with diabetic MS. IR may be responsible for multiple multihormonal dysregulation in MS.

Keywords: Metabolic syndrome; IGF-1; Cortisol/ DHEA-S ratio

\section{Introduction}

Metabolic syndrome (MS) is the complex clustering of several interrelated physiological and metabolic alterations, including insulin resistance, dyslipidemia, abdominal fat, and a proinflammatory prothrombotic state. MS is a strong risk factor for cardiovascular disease and type 2 diabetes mellitus $[1,2]$. Recent reports estimate that about one fourth of the world's adult population has MS [3], with a prevalence that increases with age and higher in men than women $[2,4]$.

Insulin like growth factor-1 (IGF-I) is the most powerful naturally-occurring peptide with glucose lowering effects after insulin [5]. IGF-1 increases insulin sensitivity and peripheral glucose uptake, decreases hepatic glucose production, and improves the lipid profile $[6,7]$. Insulin appears to be necessary for normal liver growth hormone $(\mathrm{GH})$ responsiveness, probably by maintaining liver $\mathrm{GH}$ receptor levels [8].

Dehydroepiandrosterone (DHEA) and its sulfate (DHEA-S) ester are the most abundant circulating adrenal steroids in humans [9]. DHEA-S which is converted to the active form DHEA represents the circulating hormonal pool of DHEA. DHEA is known to be a weak androgen contributing to androgenecity mainly after peripheral conversion to more potent androgens, testosterone and dihydrotestosterone. Administration of DHEA has been reported to have striking beneficial effects on obesity [10], hyperlipidemia, diabetes [11], and atherosclerosis [12] in obese rodents.

Furthermore, previous studies have suggested that low 
Table 1. Anthropometric and Biochemical Characteristics of Study Subjects

\begin{tabular}{llll}
\hline Characteristics & Group1 $(\mathbf{n}=\mathbf{3 0})$ & Group2 $(\mathbf{n}=\mathbf{3 0})$ & Group3 $(\mathbf{n}=\mathbf{4 0})$ \\
\hline Age $($ years $)$ & $42.37 \pm 5.05$ & $42.87 \pm 5.6$ & $40.4 \pm 5.9$ \\
BMI $\left(\mathrm{kg} / \mathrm{m}^{2}\right)$ & $37 \pm 5.3^{*}$ & $36.6 \pm 3.9$ & $22.2 \pm 1.5$ \\
WC $(\mathrm{cm})$ & $120.3 \pm 10.6^{*}$ & $114.4 \pm 10.4$ & $74.5 \pm 4.9$ \\
SBP $(\mathrm{mm} \mathrm{Hg})$ & $156.6 \pm 14.2^{*}$ & $151.6 \pm 12.8$ & $111 \pm 13.3$ \\
DBP $(\mathrm{mm} \mathrm{Hg})$ & $93.6 \pm 8.99^{*}$ & $92.3 \pm 6.78$ & $70.75 \pm 8.6$ \\
FBG $(\mathrm{mg} / \mathrm{dl})$ & $163.4 \pm 58.6^{*}$ & $102.3 \pm 10.98$ & $81.05 \pm 14.6$ \\
Insulin $(\mu \mathrm{d} / \mathrm{ml})$ & $25.3 \pm 4.08^{*}$ & $19.8 \pm 2.6$ & $7.4 \pm 4.6$ \\
HOMA & $10.8 \pm 3.5^{*}$ & $4.9 \pm 0.62$ & $1.4 \pm 0.84$ \\
TC $(\mathrm{mg} \%)$ & $209.7 \pm 36.8^{*}$ & $182.7 \pm 32.3$ & $157.5 \pm 27.4$ \\
TG $(\mathrm{mg} \%)$ & $155.7 \pm 55.02^{*}$ & $123.3 \pm 29.54$ & $100.6 \pm 19.5$ \\
LDL-c $(\mathrm{mg} \%)$ & $135.8 \pm 37.4^{*}$ & $118.6 \pm 28.6$ & $95.6 \pm 20.9$ \\
HDL-c $(\mathrm{mg} \%)$ & $36.5 \pm 5.1^{*}$ & $42.7 \pm 6.4$ & $52.8 \pm 2.1$ \\
IGF-1 $(\mathrm{ng} / \mathrm{ml})$ & $141.8 \pm 22.6^{*}$ & $161.7 \pm 43.6$ & $211 \pm 28.5$ \\
Cortisol $(\mathrm{nmol} / \mathrm{L})$ & $241.7 \pm 145.08^{*}$ & $159.1 \pm 39.3$ & $110.5 \pm 40.18$ \\
DHEA-S $(\mu \mathrm{mol} / \mathrm{L})$ & $0.67 \pm 0.28^{*}$ & $0.82 \pm 0.28$ & $3.2 \pm 3.4$ \\
Cortisol/DHEA-S ratio & $360.7 \pm 117.6^{*}$ & $193.8 \pm 31.6$ & $34.5 \pm 11.8$ \\
\hline
\end{tabular}

Data are expressed as mean \pm standard deviation. ${ }^{*} p \leq 0.05$, group 1 vs. group 3 ; $p \leq 0.05$, group 2 vs. group 3 ; $\uparrow p$ $\leq 0.05$, group 1 vs. group 2; Group 1: diabetic metabolic syndrome subjects; Group 2: non-diabetic metabolic syndrome subjects; Group 3: normal controls; BMI: Body mass index; WC: Waist circumference; SBP: Systolic blood pressure; DBP: Diastolic blood pressure; FBG: fasting blood glucose, HOMA: Homeostasis model assessment of insulin resistance; TC: Total cholesterol; TG: Triglyceride; LDL-c: Low density lipoprotein cholesterol; HDL-c: High density lipoprotein cholesterol; DHEA-S: dehydroepiandrosterone sulfate; IGF-1:insulin like growth factor-1.

IGF-1 and high cortisol are significant correlates of MS [13$15]$.

The aim of the present study was to examine the relationships between serum IGF-1, cortisol, DHEA-S and cortisol/ DHEA-S ratio in adult men with MS either diabetic or non-diabetic.

\section{Subjects and Methods}

One hundred adult men were enrolled in the study, divided into three groups (Table 1). Group 1 included 30 patients with diabetic MS. Group 2 included 30 patients with nondiabetic MS. Group 3 included 40 age and sex-matched healthy subjects (control group). The mean ages were 42.37 $\pm 5.05,42.87 \pm 5.6$ and $40.4 \pm 5.9$, respectively. All patients signed an informed consent to be included in our study. This study was approved by the local ethical committee of Mansoura University Hospital, Internal Medicine Department.

All participants were subjected to thorough medical history and clinical examination. Anthropometric measurements including weight, height, body mass index (BMI) calculated as weight/ height ${ }^{2}\left(\mathrm{~kg} / \mathrm{m}^{2}\right)$ and waist circumference (WC) were obtained using standardized techniques. Blood pressure was taken in the sitting position after 10-min rest using a random-zero sphygmomanometer. Exclusion criteria included the presence of renal, hepatic disease, and diabetic patients under insulin therapy.

MS was defined using the International Diabetes Federation (IDF) consensus group guidelines as abdominal obesity (WC $\geq 90 \mathrm{~cm}$ for men) plus two or more of the following risk factors: blood pressure $\geq 130 / 85 \mathrm{~mm} \mathrm{Hg}$ or taking antihypertensive medication, fasting plasma glucose $\geq 100 \mathrm{mg} /$ $\mathrm{dl}$ or pre-existing diabetes, serum triglycerides $\geq 1.7 \mathrm{mmol} / 1$ $(\geq 150 \mathrm{mg} / \mathrm{l})$ and HDL levels $<1.03 \mathrm{mmol} / 1(<40 \mathrm{mg} / \mathrm{dl})$ for men (16).

\section{Assay}

Fasting plasma glucose (FBG) was estimated using commer- 
Table 2. Correlation Between IGF-1 and Cortisol/ DHEA-S Ratio and Clinical and Metabolic Parameters in Diabetic Metabolic Syndrome Subjects

\begin{tabular}{lllll}
\hline & & IGF-1 & \multicolumn{2}{c}{ Cortisol/DHEA-S } \\
Characteristics & r & P-value & r & P-value \\
\hline BMI $\left(\mathrm{kg} / \mathrm{m}^{2}\right)$ & -0.417 & $0.03^{*}$ & 0.36 & $0.04^{*}$ \\
WC $(\mathrm{cm})$ & -0.358 & $0.05^{*}$ & 0.52 & $0.03^{*}$ \\
SBP $(\mathrm{mm} \mathrm{Hg})$ & -0.477 & $0.04^{*}$ & 0.48 & $0.03^{*}$ \\
DBP $(\mathrm{mm} \mathrm{Hg})$ & -0.615 & $<0.001^{* * *}$ & 0.67 & $0.006^{* *}$ \\
FBG $(\mathrm{mg} / \mathrm{dl})$ & -0.39 & $0.04^{*}$ & 0.44 & $0.03 *$ \\
Insulin $(\mu \mathrm{U} / \mathrm{ml})$ & -0.52 & $0.02^{*}$ & 0.55 & $0.02^{*}$ \\
HOMA & -0.78 & $<0.001^{* * *}$ & 0.63 & $0.002^{* *}$ \\
TC $(\mathrm{mg} \%)$ & -0.44 & $0.03^{*}$ & 0.46 & $0.03^{*}$ \\
TG $(\mathrm{mg} \%)$ & -0.52 & $0.02^{*}$ & 0.48 & $0.04^{*}$ \\
LDL-c $(\mathrm{mg} \%)$ & -0.59 & $0.006^{* *}$ & 0.52 & $0.03 *$ \\
HDL-c $(\mathrm{mg} \%)$ & 0.62 & $0.009^{* *}$ & -0.53 & $0.002^{*}$ \\
Cortisol $(\mathrm{nmol} / \mathrm{L})$ & -0.72 & $<0.001^{* * *}$ & 0.69 & $<0.001^{* * *}$ \\
DHEA-S $(\mu \mathrm{mol} / \mathrm{L})$ & 0.47 & $0.04^{*}$ & -0.55 & $0.003^{* *}$ \\
Cortisol/DHEA-S ratio & -0.85 & $<0.001^{* * *}$ & - & - \\
\hline
\end{tabular}

${ }^{*} \mathrm{p} \leq 0.05 ;{ }^{* *} \mathrm{p}<0.01 ;{ }^{* * *} \mathrm{p}<0.001$; BMI: Body mass index; WC: Waist circumference; SBP: Systolic blood pressure; DBP: Diastolic blood pressure; FBG: fasting blood glucose, HOMA: Homeostasis model assessment of insulin resistance; TC: Total cholesterol; TG: Triglyceride; LDL-C: Low density lipoprotein cholesterol; HDL-c: High density lipoprotein cholesterol; DHEA-S: dehydroepiandrosterone sulfate; IGF-1:insulin like growth factor-1.

cially available kit supplied by Human (Germany). Fasting serum insulin was assayed by a solid-phase and enzymelabeled chemiluminescent immunometric assay using immulite analyzer supplied by Siemens (USA). Basal insulin resistance index (HOMA) was calculated according to the formula [17]: Insulin resistance $=$ fasting insulin $(\mu \mathrm{U} /$ $\mathrm{ml}) \mathrm{x}$ fasting glucose $(\mathrm{mmol} / \mathrm{l}) / 22.5$. Serum total cholesterol (TC), triglyceride (TG), and high density lipoprotein cholesterol (HDL-c) were assayed by commercially available kits. Low density lipoprotein cholesterol (LDL-c) was calculated according to Friedewald et al. (18). Serum IGF-1 was estimated by immunoenzymometric assay supplied by Roy Bio (USA). Serum fasting cortisol and DHEA-S were determined by a solid-phase competitive chemiluminescent enzyme immunoassay using immulite analyzer supplied by Siemens (USA).

\section{Statistical analysis}

SPSS packages version 10 (spss, inc., Chicago, IL, USA) was used for the statistical analysis of data. The data were expressed as mean $( \pm)$ SD for continuous data and frequency and proportion for categorical data. For continuous data, Student's t-test was used to compare two groups. A Chisquare test was used to compare categorical data. Correlation coefficients were calculated to evaluate associations between variables. Multiple regression analysis was also performed with IGF-1 and Cortisol/ DHEA-S ratio as the dependent variables and all other variables as independent variables. $\mathrm{P}$ value of $<0.05$ indicates significant results.

\section{Results}

Baseline characteristics of the three groups are given in Table 1. Diabetic metabolic syndrome subjects (group 1) and non-diabetic metabolic syndrome subjects (group 2) had significantly higher BMI, WC, systolic and diastolic blood pressure (SBP and DBP), FBG, insulin, HOMA, TC, TG and LDL than normal controls (group 3). WC, FBG, insulin, HOMA, TC, TG and LDL were also significantly higher in group 2 than group 3. HDL-c was significantly lower in group 1 than groups 2 and 3 as well between group 2 and group 3 . 
Table 3. Multiple Regression Analysis With IGF-1 and Cortisol/ DHEA-S as the Dependent Variables and Other Parameters as the Independent Variables in Diabetic Metabolic Syndrome Subjects

\begin{tabular}{lllll}
\hline & & IGF-1 & \multicolumn{2}{c}{ Cortisol/DHEA-S } \\
Characteristics & $\boldsymbol{\beta}$ & P-value & $\boldsymbol{\beta}$ & P-value \\
\hline BMI $\left(\mathrm{kg} / \mathrm{m}^{2}\right)$ & -0.21 & 0.25 & 0.01 & 0.9 \\
WC $(\mathrm{cm})$ & -0.31 & $0.03^{*}$ & 0.06 & 0.7 \\
SBP $(\mathrm{mm} \mathrm{Hg})$ & -0.31 & $0.04^{*}$ & 0.36 & $0.02^{*}$ \\
DBP $(\mathrm{mm} \mathrm{Hg})$ & -0.37 & $0.01^{*}$ & 0.35 & $0.01^{*}$ \\
FBG $(\mathrm{mg} / \mathrm{dl})$ & -0.58 & $0.009^{* *}$ & 0.69 & $<0.001^{* * *}$ \\
Insulin $(\mu \mathrm{U} / \mathrm{ml})$ & -0.16 & 0.4 & 0.36 & $0.01 *$ \\
HOMA & -0.61 & $0.005^{* *}$ & 0.55 & $0.002^{* *}$ \\
TC $(\mathrm{mg} \%)$ & -0.14 & 0.4 & 0.05 & 0.7 \\
TG $(\mathrm{mg} \%)$ & -0.12 & 0.4 & 0.32 & $0.03^{* *}$ \\
LDL-c $(\mathrm{mg} \%)$ & -0.01 & 0.9 & 0.92 & 0.1 \\
HDL-c $(\mathrm{mg} \%)$ & 0.23 & 0.2 & -0.39 & $0.01 *$ \\
Cortisol $(\mathrm{nmol} / \mathrm{L})$ & -0.29 & $0.03^{*}$ & 0.26 & $0.04^{*}$ \\
DHEA-S $(\mu \mathrm{mol} / \mathrm{L})$ & 0.49 & $0.01^{*}$ & -0.29 & $0.04 *$ \\
Cortisol/DHEA-S ratio & -0.35 & $0.02^{*}$ & - & - \\
\hline
\end{tabular}

${ }^{*} p \leq 0.05 ;{ }^{* *} p<0.01 ;{ }^{* * *} p<0.001 ; \beta$ is standardized $\beta$ co-efficiency; BMI: Body mass index; WC: Waist circumference; SBP: Systolic blood pressure; DBP: Diastolic blood pressure; FBG: fasting blood glucose, HOMA: Homeostasis model assessment of insulin resistance; TC: Total cholesterol; TG: Triglyceride; LDL-C: Low density lipoprotein cholesterol; HDL-C: High density lipoprotein cholesterol; DHEA-S: dehydroepiandrosterone sulfate; IGF-1:insulin like growth factor-1.

IGF-1 levels were significantly lower in group 1 $(141.8 \pm 22.6)$ than groups $2(161.7 \pm 43.6)$ and $3(211 \pm$ $28.5)$ with $\mathrm{p}<0.001$ and $\mathrm{p}<0.001$ respectively; they were also significantly lower in group 2 than group $3(\mathrm{p}=0.03)$. DHEA-S levels were significantly lower in group $1(0.67 \pm$ $0.28)$ than groups $2(0.82 \pm 0.28)$ and $3(33.2 \pm 3.4)$ with $p$ $=0.04$ and $\mathrm{p}<0.001$ respectively; they were also lower in group 2 than group $3(\mathrm{p}=0.04)$. Serum cortisol and cortisol/ DHEA-S ratio were significantly higher in groups 1 and 2 than group 3; they were also higher in group 1 than group 2. Table 2 showed urivariate correlation of IGF-1 and Cortisol/ DHEA-S ratio with clinical and metabolic parameters in the adult men with diabetic MS. IGF-1 levels were negatively correlated with BMI, WC, SBP, DBP, FBG, insulin, HOMA, TC, TG, LDL-c, cortisol and cortisol/ DHEA-S and positively correlated with HDL-c and DHEA-S while cortisol/ DHEA-S were positively correlated with BMI, WC, SBP, DBP, FBG, insulin, HOMA, TC, TG, LDL-c and cortisol, and negatively correlated with HDL-c, IGF-1 and DHEA-S.

A multiple regression analysis to assess the independent effect of studied variables on IGF-1 and cortisol/ DHEA-S in group 1 was also performed. WC, SBP, DBP, FBG, HOMA, cortisol, DHEA-S and cortisol/ DHEA-S ratio remained significantly and independently correlated with IGF-1. SBP, DBP, FBG, insulin, HOMA, TG, HDL, cortisol and DHEA-S remained significantly and independently correlated with cortisol/ DHEA-S ratio in Table 3.

\section{Discussion}

The main finding of the current study was the association of both IGF-1 and Cortisol/ DHEA- ratio with MS and most of its individual components but in opposite directions. We reported an inverse relationship between IGF-1 and Cortisol/ DHEA-S ratio.

In the present study, IGF-1 was significantly lower in adult men with diabetic MS than non-diabetic MS and healthy controls. We also found significant correlations between IGF-1 and WC, BP, FBG, HOMA, cortisol and 
DHEA-S in adult men with diabetic MS.

Several epidemiological studies have linked low circulating total IGF-1 to an increased risk of the metabolic syndrome and its individual components [19-21]. In addition, patients with type 2 diabetes often exhibit reduced circulating total IGF-1 levels [14]. Lower concentrations have been also associated with obesity [22], disturbed glucose metabolism [14, 23], fasting insulin and HOMA-IR [24], high blood pressure [25], and adverse lipid profiles [22] independently of body mass.

The majority of circulating IGF-1 is bound to six IGF binding proteins (IGFBPs) that are important in determining IGF-1 availability and activity [26]. The increase in IGF-1 bioactivity in subjects with one to three components of the metabolic syndrome may be due to an insulin-mediated suppression of IGFBP-1 levels (potentially inhibitory) [27]. This is probably a compensatory mechanism to maintain normal glucose tolerance, since raised IGF-1 bioactivity improves insulin sensitivity [28]. High IGF-1 bioactivity may suppresses GH secretion as part of a negative feedback system, thereby inducing lower total IGF-1 levels [22]. This may explain why low total IGF-1 levels have been previously reported to be associated with the metabolic syndrome [21]. Moreover, chronic hyperinsulinemia induces $\mathrm{GH}$ receptor resistance; it reduces both $\mathrm{GH}$ receptor expression and signaling in the liver [29]. On the other hand, GH deficiency in humans is associated with the accumulation of visceral adipose tissue and decreases in lean body mass [30].

Glucocorticoids directly inhibit pituitary gonadotropin and growth hormone and make the target tissue of sex steroids and growth factors resistant to these substances [31]. $11 \beta$-hydroxysteroid dehydrogenase type 1 (11 $\beta$-HSD1) which catalyzes the conversion of inert cortisone to active cortisol [32] is inhibited by GH and /or IGF1 [33]. Paulsen et al. [34] found that the mRNA expression of $11 \beta$-HSD1 is negatively correlated with IGF-1, suggesting that in human adipose tissue, $11 \beta$-HSD1 is down regulated by IGF1. Furthermore, $\mathrm{GH}$ treatment in $\mathrm{GH}$ deficiency patients markedly decreases the gene expression of $11 \beta$-HSD1 in sc abdominal tissue. So, the relative insufficiency of GH seen in truncal obesity [35] may play a role in the development of the MS.

We observed that the serum cortisol levels were significantly higher in adult men with diabetic MS than non-diabetic MS and normal controls. This result was in parallel with previous preliminary data which suggested that circulating cortisol concentrations were higher in patients with MS compared with healthy subjects, both in basal conditions and during dynamic stimulation [36, 37]. In studies that included subjects with type 2 diabetes alone, elevated basal plasma cortisol levels [38] have been also reported. In contrast, some studies have reported no association between cortisol and MS [39, 40].

Stress and hyperactivation of the hypothalamic-pituitary- adrenal axis have been observed in patients with MS [13]. Recent studies have suggested that a subtle increase in plasma cortisol might underlie the cluster of cardiovascular risk factors comprising the MS. Higher cortisol concentrations are related to reduced insulin secretion, a finding consistent with in vivo and in vitro data showing that glucocorticoids regulate insulin secretion [41]. Interestingly, cortisol clearance seems to be inversely correlated with insulin sensitivity, and this correlation is independent of body fat [42]. On the other hand, glucocorticoids regulate adipose tissue differentiation, function and distribution, and when in excess, cause central obesity, which is one of the main features of MS [43].

Our results also showed significant reduction of DHEA-S levels in adult men with diabetic MS than nondiabetic and normal controls. It has been postulated that low levels of DHEA-S are associated with unfavorable levels of several strong cardiovascular risk factors, such as lipids [44], blood pressure [45] and IR [46] which are components of the metabolic syndrome [47, 48]. Furthermore, Muller et al. [49] suggested that lower DHEA-S concentrations characterize individual with MS. However, this is not a universal observation $[39,40]$.

Both cortisol and DHEA/DHEA-S secretion are under the regulatory influence of pituitary $\mathrm{ACTH}$, and excessive cortisol production will lead to a down-regulation of ACTH, resulting in reduced DHEA secretion, as frequently observed in patients with an adrenal cortisol-producing adenoma. The protective effect indicated by higher DHEA-S is particularly interesting, and the anti-glucocorticoid actions of its precursor, DHEA, are well documented [50, 51]. Higher levels of DHEA or DHEA-S might lead to lower effective cortisol action, particularly at a tissue-specific level, e.g. adipose tissue and immune cells [52]. Indeed, Butcher et al. [53] showed that DHEA-S can overcome the suppressive effects of cortisol upon immune cell function, specifically the generation of superoxide by neutrophils, supporting the proposal that it is the ratio of these two hormones that will determine biological outcome in vivo [54]. Furthermore, DHEA-S supplementation improves endothelial function and insulin sensitivity in men [55]. DHEA-S also plays a role in prevention of platelet aggregation [56], reduction of cholesterol uptake [12] and decrease of vascular smooth muscle cells proliferation [57].

We confirmed significant elevation of Cortisol/ DHEA-S ratio in adult men with diabetic MS than non-diabetic MS and normal controls. In addition, we found significant independent correlations between Cortisol/ DHEA-S and BP, FBG, HOMA, TG and HDL in diabetic MS. These results are consistent with those from a study by Phillips et al. [58], who demonstrated that the Cortisol/ DHEA-S ratio was positively associated with MS and the ratio was significantly related to most of its individual components.

Multiple regression analysis revealed that IGF-1 and 
Cortisol/ DHEA-S were independently correlated with each other and with IR in adult men with MS. Thus Cortisol/ DHEA-S excess, IGF-1 deficiency and IR associated with MS seem evidently coherent.

The favorable effect of insulin sensitizers and lifestyle modifications need to be the focuses of advice in those patients.

\section{Conclusion}

IGF-1 concentration is reduced and cortisol/ DHEA-S ratio is increased along with insulin resistance in adult men with diabetic MS. IR may be responsible for multiple multihormonal dysregulation in MS.

\section{Competing Interests}

The authors declare that they have no competing interests.

\section{References}

1. Sattar N, Gaw A, Scherbakova O, Ford I, O’Reilly DS, Haffner SM, Isles C, et al. Metabolic syndrome with and without C-reactive protein as a predictor of coronary heart disease and diabetes in the West of Scotland Coronary Prevention Study. Circulation. 2003;108(4):414419.

2. Scuteri A, Najjar SS, Morrell CH, Lakatta EG. The metabolic syndrome in older individuals: prevalence and prediction of cardiovascular events: the Cardiovascular Health Study. Diabetes Care. 2005;28(4):882-887.

3. Kolovou GD, Anagnostopoulou KK, Salpea KD, Mikhailidis DP. The prevalence of metabolic syndrome in various populations. Am J Med Sci. 2007;333(6):362-371.

4. Ford ES, Giles WH, Dietz WH. Prevalence of the metabolic syndrome among US adults: findings from the third National Health and Nutrition Examination Survey. JAMA. 2002;287(3):356-359.

5. Boulware SD, Tamborlane WV, Matthews LS, Sherwin RS. Diverse effects of insulin-like growth factor I on glucose, lipid, and amino acid metabolism. Am J Physiol. 1992;262(1 Pt 1):E130-133.

6. Moses AC, Young SC, Morrow LA, O’Brien M, Clemmons DR. Recombinant human insulin-like growth factor I increases insulin sensitivity and improves glycemic control in type II diabetes. Diabetes. 1996;45(1):91-100.

7. Schoenle EJ, Zenobi PD, Torresani T, Werder EA, Zachmann M, Froesch ER. Recombinant human insulin-like growth factor I (rhIGF I) reduces hyperglycaemia in patients with extreme insulin resistance. Diabetologia. 1991;34(9):675-679.

8. Bereket A, Lang CH, Blethen SL, Gelato MC, Fan J,
Frost RA, Wilson TA. Effect of insulin on the insulinlike growth factor system in children with new-onset insulin-dependent diabetes mellitus. J Clin Endocrinol Metab. 1995;80(4):1312-1317.

9. Melby JC. Assessment of adrenocortical function. N Engl J Med. 1971;285(13):735-739.

10. Yen TT, Allan JA, Pearson DV, Acton JM, Greenberg MM. Prevention of obesity in Avy/a mice by dehydroepiandrosterone. Lipids. 1977;12(5):409-413.

11. Coleman DL, Schwizer RW, Leiter EH. Effect of genetic background on the therapeutic effects of dehydroepiandrosterone (DHEA) in diabetesobesity mutants and in aged normal mice. Diabetes. 1984;33(1):26-32.

12. Gordon GB, Bush DE, Weisman HF. Reduction of atherosclerosis by administration of dehydroepiandrosterone. A study in the hypercholesterolemic New Zealand white rabbit with aortic intimal injury. J Clin Invest. 1988;82(2):712-720.

13. Bjorntorp P, Rosmond R. The metabolic syndrome-a neuroendocrine disorder? Br J Nutr. 2000;83 Suppl 1:S49-57.

14. Sandhu MS, Heald AH, Gibson JM, Cruickshank JK, Dunger DB, Wareham NJ. Circulating concentrations of insulin-like growth factor-I and development of glucose intolerance: a prospective observational study. Lancet. 2002;359(9319):1740-1745.

15. Sesti G, Sciacqua A, Cardellini M, Marini MA, Maio R, Vatrano M, Succurro E, et al. Plasma concentration of IGF-I is independently associated with insulin sensitivity in subjects with different degrees of glucose tolerance. Diabetes Care. 2005;28(1):120-125.

16. International Diabetes Federation. New IDF worldwide definition of the metabolic syndrome. Press Conference 1st International Congress on 'Pre-diabetes' and the Metabolic Syndrome, Berlin, Germany. 2005.

17. Matthews DR, Hosker JP, Rudenski AS, Naylor BA, Treacher DF, Turner RC. Homeostasis model assessment: insulin resistance and beta-cell function from fasting plasma glucose and insulin concentrations in man. Diabetologia. 1985;28(7):412-419.

18. Friedewald WT, Levy RI, Fredrickson DS. Estimation of the concentration of low-density lipoprotein cholesterol in plasma, without use of the preparative ultracentrifuge. Clin Chem. 1972;18(6):499-502.

19. Kaushal K, Heald AH, Siddals KW, Sandhu MS, Dunger DB, Gibson JM, Wareham NJ. The impact of abnormalities in IGF and inflammatory systems on the metabolic syndrome. Diabetes Care. 2004;27(11):2682-2688.

20. Saydah S, Graubard B, Ballard-Barbash R, Berrigan D. Insulin-like growth factors and subsequent risk of mortality in the United States. Am J Epidemiol. 2007;166(5):518-526.

21. Sierra-Johnson J, Romero-Corral A, Somers VK, Lopez- 
Jimenez F, Malarstig A, Brismar K, Hamsten A, et al. IGF-I/IGFBP-3 ratio: a mechanistic insight into the metabolic syndrome. Clin Sci (Lond). 2009;116(6):507512.

22. Sandhu MS, Gibson JM, Heald AH, Dunger DB, Wareham NJ. Association between insulin-like growth factor-I: insulin-like growth factor-binding protein-1 ratio and metabolic and anthropometric factors in men and women. Cancer Epidemiol Biomarkers Prev. 2004;13(1):166-170.

23. Juul A. Serum levels of insulin-like growth factor I and its binding proteins in health and disease. Growth Horm IGF Res. 2003;13(4):113-170.

24. Frystyk J, Skjaerbaek C, Vestbo E, Fisker S, Orskov H. Circulating levels of free insulin-like growth factors in obese subjects: the impact of type 2 diabetes. Diabetes Metab Res Rev. 1999;15(5):314-322.

25. Capoluongo E, Pitocco D, Lulli P, Minucci A, Santonocito C, Manto A, Di Stasio E, et al. Inverse correlation between serum free IGF-I and IGFBP-3 levels and blood pressure in patients affected with type 1 diabetes. Cytokine. 2006;34(5-6):303-311.

26. Baxter RC. Insulin-like growth factor (IGF)-binding proteins: interactions with IGFs and intrinsic bioactivities. Am J Physiol Endocrinol Metab. 2000;278(6):E967-976.

27. Lee PD, Giudice LC, Conover CA, Powell DR. Insulin-like growth factor binding protein-1: recent findings and new directions. Proc Soc Exp Biol Med. 1997;216(3):319-357.

28. Clemmons DR. Involvement of insulin-like growth factor-I in the control of glucose homeostasis. Curr Opin Pharmacol. 2006;6(6):620-625.

29. Ji S, Guan R, Frank SJ, Messina JL. Insulin inhibits growth hormone signaling via the growth hormone receptor/JAK2/STAT5B pathway. J Biol Chem. 1999;274(19):13434-13442.

30. Nam SY, Lee EJ, Kim KR, Cha BS, Song YD, Lim SK, Lee HC, et al. Effect of obesity on total and free insulin-like growth factor (IGF)-1, and their relationship to IGF-binding protein (BP)-1, IGFBP-2, IGFBP-3, insulin, and growth hormone. Int J Obes Relat Metab Disord. 1997;21(5):355-359.

31. Chrousos GP. The role of stress and the hypothalamicpituitary-adrenal axis in the pathogenesis of the metabolic syndrome: neuro-endocrine and target tissue-related causes. Int J Obes Relat Metab Disord. 2000;24 Suppl 2:S50-55.

32. Wake DJ, Walker BR. 11 beta-hydroxysteroid dehydrogenase type 1 in obesity and the metabolic syndrome. Mol Cell Endocrinol. 2004;215(1-2):45-54.

33. Tomlinson JW, Moore J, Cooper MS, Bujalska I, Shahmanesh M, Burt C, Strain A, et al. Regulation of expression of 11beta-hydroxysteroid dehydrogenase type 1 in adipose tissue: tissue-specific induction by cytokines.
Endocrinology. 2001;142(5):1982-1989.

34. Paulsen SK, Pedersen SB, Jorgensen JO, Fisker S, Christiansen JS, Flyvbjerg A, Richelsen B. Growth hormone $(\mathrm{GH})$ substitution in $\mathrm{GH}$-deficient patients inhibits 11 beta-hydroxysteroid dehydrogenase type 1 messenger ribonucleic acid expression in adipose tissue. J Clin Endocrinol Metab. 2006;91(3):1093-1098.

35. Miller KK, Biller BM, Lipman JG, Bradwin G, Rifai N, Klibanski A. Truncal adiposity, relative growth hormone deficiency, and cardiovascular risk. J Clin Endocrinol Metab. 2005;90(2):768-774.

36. Phillips DI, Barker DJ, Fall CH, Seckl JR, Whorwood CB, Wood PJ, Walker BR. Elevated plasma cortisol concentrations: a link between low birth weight and the insulin resistance syndrome? J Clin Endocrinol Metab. 1998;83(3):757-760.

37. Weigensberg MJ, Toledo-Corral CM, Goran MI. Association between the metabolic syndrome and serum cortisol in overweight Latino youth. J Clin Endocrinol Metab. 2008;93(4):1372-1378.

38. Lee ZS, Chan JC, Yeung VT, Chow CC, Lau MS, Ko GT, Li JK, et al. Plasma insulin, growth hormone, cortisol, and central obesity among young Chinese type 2 diabetic patients. Diabetes Care. 1999;22(9):1450-1457.

39. Maggio M, Lauretani F, Ceda GP, Bandinelli S, Basaria S, Ble A, Egan J, et al. Association between hormones and metabolic syndrome in older Italian men. J Am Geriatr Soc. 2006;54(12):1832-1838.

40. Maggio M, Lauretani F, Ceda GP, Bandinelli S, Basaria S, Paolisso G, Ble A, et al. Association of hormonal dysregulation with metabolic syndrome in older women: data from the InCHIANTI study. Am J Physiol Endocrinol Metab. 2007;292(1):E353-358.

41. Delaunay F, Khan A, Cintra A, Davani B, Ling ZC, Andersson A, Ostenson CG, et al. Pancreatic beta cells are important targets for the diabetogenic effects of glucocorticoids. J Clin Invest. 1997;100(8):2094-2098.

42. Holt HB, Wild SH, Postle AD, Zhang J, Koster G, Umpleby M, Shojaee-Moradie F, et al. Cortisol clearance and associations with insulin sensitivity, body fat and fatty liver in middle-aged men. Diabetologia. 2007;50(5):1024-1032.

43. Bujalska IJ, Kumar S, Stewart PM. Does central obesity reflect "Cushing's disease of the omentum"? Lancet. 1997;349(9060):1210-1213.

44. Tchernof A, Labrie F, Belanger A, Prud'homme D, Bouchard C, Tremblay A, Nadeau A, et al. Relationships between endogenous steroid hormone, sex hormonebinding globulin and lipoprotein levels in men: contribution of visceral obesity, insulin levels and other metabolic variables. Atherosclerosis. 1997;133(2):235-244.

45. Barrett-Connor E, Khaw KT. Endogenous sex hormones and cardiovascular disease in men. A prospective population-based study. Circulation. 1988;78(3):539-545. 
46. Haffner SM, Valdez RA, Mykkanen L, Stern MP, Katz MS. Decreased testosterone and dehydroepiandrosterone sulfate concentrations are associated with increased insulin and glucose concentrations in nondiabetic men. Metabolism. 1994;43(5):599-603.

47. Haffner SM, Karhapaa P, Mykkanen L, Laakso M. Insulin resistance, body fat distribution, and sex hormones in men. Diabetes. 1994;43(2):212-219.

48. Abate N, Haffner SM, Garg A, Peshock RM, Grundy SM. Sex steroid hormones, upper body obesity, and insulin resistance. J Clin Endocrinol Metab. 2002;87(10):45224527.

49. Muller M, Grobbee DE, den Tonkelaar I, Lamberts SW, van der Schouw YT. Endogenous sex hormones and metabolic syndrome in aging men. J Clin Endocrinol Metab. 2005;90(5):2618-2623.

50. Kalimi M, Shafagoj Y, Loria R, Padgett D, Regelson W. Anti-glucocorticoid effects of dehydroepiandrosterone (DHEA). Mol Cell Biochem. 1994;131(2):99-104.

51. Kimonides VG, Spillantini MG, Sofroniew MV, Fawcett JW, Herbert J. Dehydroepiandrosterone antagonizes the neurotoxic effects of corticosterone and translocation of stress-activated protein kinase 3 in hippocampal primary cultures. Neuroscience. 1999;89(2):429-436.

52. Hazeldine J, Arlt W, Lord JM. Dehydroepiandrosterone as a regulator of immune cell function. $\mathrm{J}$ Steroid Biochem
Mol Biol. 2010;120(2-3):127-136.

53. Butcher SK, Killampalli V, Lascelles D, Wang K, Alpar EK, Lord JM. Raised cortisol:DHEAS ratios in the elderly after injury: potential impact upon neutrophil function and immunity. Aging Cell. 2005;4(6):319-324.

54. Butcher SK, Lord JM. Stress responses and innate immunity: aging as a contributory factor. Aging Cell. 2004;3(4):151-160.

55. Kawano H, Yasue H, Kitagawa A, Hirai N, Yoshida T, Soejima H, Miyamoto S, et al. Dehydroepiandrosterone supplementation improves endothelial function and insulin sensitivity in men. J Clin Endocrinol Metab. 2003;88(7):3190-3195.

56. Jesse RL, Loesser K, Eich DM, Qian YZ, Hess ML, Nestler JE. Dehydroepiandrosterone inhibits human platelet aggregation in vitro and in vivo. Ann N Y Acad Sci. 1995;774:281-290.

57. Williams MR, Ling S, Dawood T, Hashimura K, Dai A, Li H, Liu JP, et al. Dehydroepiandrosterone inhibits human vascular smooth muscle cell proliferation independent of ARs and ERs. J Clin Endocrinol Metab. 2002;87(1):176-181.

58. Phillips AC, Carroll D, Gale CR, Lord JM, Arlt W, Batty GD. Cortisol, DHEAS, their ratio and the metabolic syndrome: evidence from the Vietnam Experience Study. Eur J Endocrinol. 2010;162(5):919-923. 